NOTAS

\title{
LAS RELACIONES \\ ENTRE MÉXICO Y RUSIA 1741-1991 \\ Y SU IMPACTO EN MÉXICO
}

Evgueni Dik*

El presente trabajo busca exponer el carácter e influencia de las relaciones con Rusia, y más tarde con la URSS, sobre la política y en especial las relaciones internacionales de México desde la segunda mitad del siglo XVIII a la fecha.

Así, el marco cronológico de este tema abarca desde el acercamiento ruso-novohispano en el Septentrión del Pacífico anunciado por la segunda expedición de Bering de 1741, hasta el colapso del Estado soviético en 1991.

$$
* * *
$$

Vale la pena mencionar que no faltan estudios tanto en la historiografía rusa-soviética como mexicana, española y norteamericana sobre la

* Departamento Académico de Estudios Internacionales, ITAM. historia de estas relaciones, su contenido y curso, así como la mutua percepción histórico-cultural de ambas naciones, que por cierto han compartido algunos rasgos semejantes en su trayecto histórico. Ambas naciones sufrieron el impacto de la occidentalización, así como la servidumbre, la encomienda, el oscurantismo religioso y la opresión gubernamental. Asimismo, el tardío desarrollo industrial, la falta de instituciones democráticas arraigadas, el fenómeno cultural y político de la intelligentsia, el específico papel del autoritarismo, como la práctica y cultura políticas, permiten trazar líneas paralelas de los respectivos destinos de México y Rusia, pero también marcar una diferencia fundamental entre ambas naciones.

Mientras que el primero nació como una "invención española" 
NOTAS

(O'Gorman) en el Nuevo Mundo, fruto de la Conquista y el mestizaje, que se consolidó como la rica y vasta colonia de ta Nueva España, y más tarde fue un país atado por los lazos de la dependencia económica y política de emporios como Gran Bretaña y después los Estados Unidos de América; por su lado, Rusia se mantuvo siempre como un Estado independiente, imperio mundial y potencia global.

Sin embargo, y no obstante los análisis de diversos aspectos de la relación ruso-mexicana -políticos, económicos, culturales, ideológicos e incluso migratorios- aún falta explicar en qué forma la relación con Rusia influenciaba la conducta de México tanto en la palestra internacional como en el contexto de sus cambios internos.

Si bien la relación entre las dos naciones puede verse como una vinculación arraigada y sólida, desarrollada en el marco de una "mutua fascinación" y la presencia de factores históricos semejantes en la consolidación de ambos países, no hay que olvidar que México hasta los últimos años no se perfilaba como un actor verdaderamente independiente, siendo más bien objeto que sujeto en esta relación. Al igual que con el Imperio Británico, los Estados Unidos, Francia y Alemania, la relación mexicana con Rusia, seguía los tér- minos generales de los patrones tradicionales de la relación de una gran potencia con una nación dependiente $o$, según el vocabulario marxista, "semicolonial".

Desde su surgimiento como entidad política, México no era plenamente independiente desde el punto de vista de sus realidades geopolíticas y de su marco de negociación diplomática. Mientras tanto, Rusia que a lo largo de los siglos XVIII y XIX constituía una de las grandes potencias imperiales, en el siglo $\mathrm{XX}$ deja de existir como un estado-nación o un estado-imperio (en el sentido tradicional de este concepto) y se transforma con la revolución socialista de 1917 en una potencia con una estructura interna y una "misión" externa basadas en la utopía ideológica del Comunismo.

EIEstado Soviético desafiaba abiertamente al "orden burgués", tanto interno como de las relaciones internacionales, y veía al mundo como un campo de batalla ideológica permanente en aras de la lucha por el triunfo del Comunismo a nivel global. (Sólo con la política de Perestroika la URSS rechaza de hecho y de facto el patrón ideológico de su anterior política internacional). La nueva Rusia Soviética que surgió en 1917, tuvo una influencia universal sobre muchos ámbitos del sistema de relaciones internacionales 
(Comintern, Segunda Guerra Mundial, Guerra Fría). Para nuestro caso es de particular interés tomar en consideración la influencia que ejercía el "ejemplo soviético" sobre las naciones en vías de desarrollo. El Socialismo a la Sovietique se visualizaba como una alternativa al capitalismo, el imperialismo y la dependencia, mientras que al mismo tiempo se consideraba como instrumento de modernización para las sociedades subdesarrolladas.

$* * *$

Acercándonos al proceso de la relación ruso-mexicana, podemos ver que ésta se remonta al siglo XVIII cuando empezó a perfilarse dentro de la relación ruso-española $y$, por consiguiente, ruso-novohispana.

La segunda etapa de la relación entre las dos naciones cae en el período del México independiente a lo largo del siglo XIX y principios del XX (1821-1910) que evolucionó a través del Imperio, la República criolla, el proyecto liberal, "la monarquía extranjera" y finalmente la dictadura unificadora conocida como Porfiriato. Durante estas convulsivas transformaciones de México, Rusia se mantuvo firme como una gran potencia e imperio multinacional y también experimentó diversos cambios reformistas y revolucionarios (1905); un Estado imperialista en rivalidad con las grandes potencias de la época: el Imperio Británico, Francia y el Imperio alemán del Segundo Reich.

La tercera etapa de la relación ruso-mexicana se inicia con el triunfo del comunismo en Rusia en 1917 y perdura hasta el colapso del totalitarismo soviético en 1991.

Actualmente las relaciones entre México y Rusia transitan hacia una nueva etapa, cuya diferencia fundamental con las anteriores consiste en el hecho de que con el fin del imperio soviético y el cambio hacia el libre mercado y la democracia en Rusia, ésta pierde tamaño como potencia mundial y sus pretensiones mesiánicas globales y, al mismo tiempo, México deja de ser simple objeto en la relación. Rusia, que evoluciona hacia el capitalismo, tiende hacia un desarrollo al estilo del Tercer Mundo (con una renta per cápita en 1992 semejante a la de México: 2870 dól.). ${ }^{1}$

Dentro de la nueva coyuntura internacional y por los cambios internos en Rusia, México está estableciendo una relación realista y pragmática con aquel país, como un socio semejante $\mathrm{e}$ independiente.

A lo largo de las etapas mencionadas, la relación con Rusia tuvo diferente importancia para México, re-

${ }^{1}$ Excélsior, 2 de septiembre, 1993. 
NOTAS

flejada tanto en su agenda interna como externa.

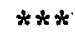

Por lo que toca a la primera etapa de las relaciones (1741-1821), la influencia rusa sobre el Virreinato de la Nueva España tuvo una enorme consecuencia geopolítica: el desplazamiento español hacia el Septetrión del Pacífico en la segunda mitad del siglo XVIII y las reformas borbónicas encabezadas por el Visitador de Su Majestad, don José de Gálvez.

El acercamiento ruso hacia el Continente Americano se remonta hasta la primera mitad del siglo XVII, con el establecimiento en la costa del Pacifico Norte (1639) y el descubrimiento del Estrecho entre América y el Continente Asiático por el navegante Semion Dieshnev en 1648. La consolidación del Imperio Ruso como una gran potencia europea, con los designios imperialistas a nivel global durante el reinado de Pedro el Grande (1682-1725) dio un nuevo impulso a la expansión rusa en el Pacífico. En este contexto, la primera expedición de Bering en 1728 ya tuvo como objetivo la navegación por el Pacífico hacia los dominios europeos, es decir españoles, más cercanos. Sin embargo, sólo con la segunda expedición de Bering en 1741 los rusos lograron las cos- tas americanas (islas Aleutianas) y veinte años más tarde descubrirán Alaska. Así, en el transcurso de los años 40 y 60 del siglo XVIII, los rusos desafiarían con su asentamiento en el extremo norte del Continente Americano, el principio fundamental de la presencia española en el Nuevo Mundo, según el cual las tierras descubiertas por un soberano cristiano le pertenecían hasta las fronteras con posesiones de otro soberano cristiano.

Por lo tanto, la defensa de "Nuestra América" en contra de las incursiones extranjeras comprendía una de las obligaciones principales de la Corona Española en el Nuevo Mundo. La creciente penetración rusa hacia el Septentrión y un posible desplazamiento hacia las costas de California se consideraban en Madrid y en México como una nueva amenaza a los dominios españoles, comparable con las de los ingleses y franceses. Vale la pena recordar que no faltaban en la Nueva España las voces (en especial de los frailes) que acentuaban la dimensión de esta amenaza rusa. ${ }^{2}$ La reacción española no tardó en concretarse en medidas urgentes y coherentes. Así, el factor ruso jugó un papel de suma

${ }^{2}$ Véase: Volk1, Ekkehard, Russian und Latinamerika, 1741-1841, 1968, Weisbaden, p. 46. 
importancia en el contexto de las reformas administrativas y militares en la Nueva España dirigidas por el visitador Gálvez y ejecutadas por los Virreyes de Croix (1768-1771) y Antonio María de Bucareli (17711779). El avance español hacia California también recibió un nuevo impulso, debido al temor de que esta región pudiera pasar a manos de los rusos y convertirse en una especie de Nueva Rusia, a imitación de la Nueva España. Entre 1769 y 1776 los españoles fundaron sus establecimientos en la Alta California (San Diego, Monterrey y San Francisco) y lanzaron una serie de expediciones marítimas con rumbo al Norte del Pacífico.

Las vagas nociones geográficas y noticias inciertas sobre el avance ruso estimularon aún más estas respuestas novo-hispanas. La desconfianza española y el deseo de evitar la presencia rusa en América quedó plasmada en las instrucciones de Bucareli al Comandante Juan Pérez, jefe de la expedición marítima española de 1774 en el Septentrión: "Al descubrir algún establecimiento extranjero tomará mayor altura para desembarcar y empezar la ceremonia de posesión." ${ }^{3}$ En 1779 los barcos españoles lograron Alaska y en

${ }^{3}$ Archivo General de la Nación, T. 61, exp. 31, F. 90-90 dorso.
1788 los rusos fueron "descubiertos" por el capitán Esteban Martínez, quien estableció contacto con ellos cerca de la isla Kodiak. Sin embargo, mientras que el empuje ruso cobraba una mayor fuerza, la presencia española en el norte del Continente Americano no pudo extenderse ni consolidarse. Su expulsión de la Bahía de Nutka en 1790 por los ingleses finalizó la aventura. Esta capitulación de Madrid frente al avance inglés en el Septentrión propició la penetración rusa, ya que el acuerdo anglo-hispano sobre la frontera española en esta zona les garantizó la posibilidad de expandirse sin chocar en forma directa con los intereses españoles. ${ }^{4}$

También cabe mencionar que el floreciente comercio peletero ruso en la cuenca del Pacífico en el siglo XVIII y principios del XIX, que se consolidó con el establecimiento de la Compañía Ruso-Americana, tuvo un impacto indirecto sobre la economía de la Nueva España, obligando a Madrid y a México a diseñar planes del comercio peletero en el Septentrión que contuvieran el avance ruso. ${ }^{5}$

${ }^{4}$ Ortega, M., Un siglo de la expansión rusa en el Pacífico: 1741-1841, Relaciones Internacionales, 44-45, 1988, p. 64.

${ }^{5}$ Véase: Cárdenas, H., Historia de las relaciones entre México y Rusia, 1993, p. 48-9. 
NOTAS

Así, en la época colonial México y Rusia entraron en una relación caracterizada por una mutua desconfianza y competencia. Madrid, y por ende Nueva España, fueron obligadas a tomar medidas de precaución y prepararse para una contención de la expansión rusa en América.

La segunda etapa de la relación entre Rusia y México al principio no era menos controvertida y complicada.

Dada la importancia de Rusia en las relaciones internacionales de aquella época y en especial gracias a su liderazgo en la Santa Alianza, los patriotas mexicanos buscaban un acercamiento con Petersburgo para obtener garantía de su neutralidad y "comprensión" en el conflicto con Madrid. Surgió incluso en 1815 el proyecto de involucrar a Rusia en la guerra por la independencia de México al lado de los insurgentes, ofreciendo al hermano del Zar ruso, Nicolás (más tarde el emperador Nicolás I, 1825-1855) la "corona mexicana". ${ }^{6}$ Sin embargo, el gobierno del Zar nunca dio signos de simpatía con la rebelión. Al mismo tiempo, la gran influencia que ejercía el gobierno ruso sobre España tenía una importancia vital para la causa insurgente mexicana; su moderada posición respecto de los lla-

${ }^{6}$ Vneshniaia Politica Rossii, serie II, t.I, 1974, Moscú, p. 524-5, 713, 257-64. mamientos españoles de obtener ayuda contra los revolucionarios, así como la inclinación de Alejandro I a favor de una solución diplomática entre Madrid y los insurgentes, era de un enorme peso para los patriotas mexicanos e hispanoamericanos en general en sus luchas independentistas. $^{7}$

Mientras tanto, con la consolidación de México como nación independiente, las nuevas autoridades mexicanas tuvieron que enfrentar la delicada cuestión geopolítica de la existencia de una frontera entre México y Rusia ubicada en la región de la Bahía de Bodega, cerca de San Francisco. La presencia allí de una pequeña fortaleza rusa, Fort Ross desde 1812, ya había sido un dolor de cabeza para la administración colonial californiana, que heredó la administración de México independiente. A pesar de que para la tercera década del siglo XIX las actividades comerciales rusas en California se encontraban en franca decadencia, el rechazo del gobierno zarista a reconocer la independencia mexicana y el conservadurismo de Nico-

${ }^{7}$ Véase respecto de la política rusa: Sliozkin L.Y., Rossiia y Voina, Nezavisimost v Ispanoskoi Amerike, 1964, Moscú; Russel H., Bartley, Imperial Russia and the Struggle for Latin American Independence, 18081828,1978 , Austin. 


\section{NOTAS}

lás I obligó al gobierno de México a buscar contener el posible avance ruso en la zona, con el apoyo de los Estados Unidos y más tarde atrayendo a colonos norteamericanos. ${ }^{8} \mathrm{Sin}$ embargo, eran razones meramente económicas, en particular la decadencia de los recursos peleteros en la Alta California, los que decidieron a los rusos a abandonar la región para 1842. Pocos años más tarde los norteamericanos, presuntos "defensores" de la soberanía mexicana, se apoderaron de toda la enorme extensión territorial de México al norte del Río Bravo.

Esta tragedia mexicana, así como el abandono de los intereses comerciales rusos en el Pacífico, que culminó con la venta de Alaska a los Estados Unidos en 1867, alejaron a Rusia de México.

Mientras tanto, para cualquier gobierno mexicano la existencia de una relación con el imperio de los zares era tanto un factor de prestigio como de una política de balance contra las potencias que podían amenazar la independencia de México. La búsqueda de una proximidad con Rusia como un contrapeso de los intereses franceses, ingleses y norteamericanos, constituyó el motivo principal de esta relación por más de un siglo. Por ejemplo, a pesar del re-

\footnotetext{
${ }^{8}$ Cárdenas, H., ibid., p. 8, 83-6.
}

conocimiento ruso del Imperio de Maximiliano, la diplomacia republicana mexicana pudo asegurar que Rusia no formalizara esta relación enviando a México un agente diplomático ni prestando apoyo a la aventura francesa.

El establecimiento de las relaciones entre México y Rusia también se ubicó en el contexto de la rivalidad y amenaza del tercer actor en aquellas circunstancias, el Imperio Británico. México, irritado por la presencia británica en Belice y por el apoyo del que gozaban los piratas beliceños por parte de Londres, ideaba su relación con Petersburgo como un posible contrapeso al imperialismo británico.

Si bien el papel de Rusia para México en estas primeras dos etapas tuvo cierta dimensión geopolítica, con los triunfos de la Revolución Socialista de 1917 y, antes, de la Revolución Mexicana, el carácter y la influencia rusa sobre México logra un nuevo peso debido al alto contenido ideológico que empezó a infiltrar todo el sistema de las relaciones entre ambas naciones.

Es importante tener en cuenta que el gobierno mexicano, independientemente de sus inclinaciones y simpatías ideológicas, seguía viendo su relación con Rusia como contrapeso a la hegemonía de los Estados Unidos. 
NOTAS

En este contexto, el presidente Carranza coqueteaba con los emergentes comunistas mexicanos, quienes gozaban de todo tipo de apoyo soviético. Carranza, de hecho, dio luz verde para la formación del Partido Comunista Mexicano, fundado con la activa participación extranjera, en especial del conocido agente del Comintern, Borodin, y en abierta violación a la recién firmada Constitución mexicana. ${ }^{9} \mathrm{El}$ impacto de la Revolución rusa sobre México fue manifiesto no sólo con la aparición del PCM, sino con el surgimiento del anticomunismo mexicano y una política norteamericana aún más insidiosa hacia el régimen revolucionario de México. México fue el primer país del Continente americano que estableció relaciones diplomáticas con la URSS, en 1924.

Sin embargo, la percepción del gobierno mexicano como "burgués" y "reaccionario" por los comunistas mexicanos y a fin de cuenta por la URSS, hizo que las relaciones soviético-mexicanas resultaran minadas. El disfrazado apoyo soviético a la izquierda mexicana y el riguroso alineamiento de gran parte de ésta a Moscú, provocó en 1930 la ruptura de las relaciones entre ambos países. El caso de Trotski agravó la si-

${ }^{9}$ Véase más detallado: Cárdenas, ibid., p. 147-58. tuación, si bien la presencia de este gran revolucionario tuvo un papel significativo en el desarrollo de la izquierda mexicana.

Con el restablecimiento de las relaciones entre la URSS y México en 1943, durante la Segunda Guerra Mundial la influencia soviética en México empieza a retomar fuerza. Sin embargo, durante las décadas siguientes las corrientes izquierdistas e intelectuales pro-soviéticas no representaban una amenaza candente al régimen del partido oficial. Más aún, el mexicano procuraba perfilarse como un genuino Gobierno de izquierda, uno de los líderes del Movimiento de No Alineación, apoyando a Cuba y después a Nicaragua, en contra de los Estados Unidos. En este contexto la relación con la URSS constituyó uno de los pilares de su política.

El presidente Echeverría fue un verdadero artífice de esta política y desde su visita oficial a Moscú en 1973, los sucesivos presidentes de México visitaron el Kremlin, con excepción de Miguel de la Madrid.

Sin embargo, mientras el carácter bilateral de las relaciones mexicano-soviéticas aparentaban confirmar la idea de una genuina amistad entre ambos países, la influencia del comunismo soviético en México afectaba seriamente tanto al carácter de esta relación como a la situa- 
ción interna de México. Aún más, en 1971, a pocos meses de tomar el poder, Echeverría enfrentó un grave conflicto en sus relaciones con la URSS, al descubrirse la vinculación de un grupo guerrillero mexicano con la Embajada soviética en México. ${ }^{10}$ A su vez, tras un oficial y popular anti-americanismo mexicano, la influencia cultural, ideológica e incluso política soviética tuvo una importante presencia. Entre los años 70 y 80 ser pro-soviético significaba ser progresista no sólo en el ámbito de la izquierda intelectual, sino en los círculos gubernamentales mexicanos.

La Perestroika y Glasnost, así como la crisis soviética también tuvieron un impacto significativo para México. Éste no sólo se reflejó en la crisis y pérdida de la orientación ideológica de la izquierda mexicana, lo que últimamente se reflejó en el surgimiento del Movimiento Zapatista en Chiapas, sino que también afectó severamente a la política de balance y contrapeso que ejercía México en sus relaciones internacionales gracias al factor soviético, en especial con los Estados Unidos.

El avance democrático y por ende la crisis de la Federación Soviética, así como de toda la estructura política de la URSS, tuvieron una influencia

${ }^{10}$ Cfr. Tiempo, 29 de marzo, 1971. significativa sobre la elaboración de las reformas mexicanas llamadas en algún momento "Salinostroika". La prioridad del avance económico frente a las reformas políticas y no al contrario, como en la Perestroika soviética, fue un pilar fundamental en toda la política del sexenio de Salinas de Gortari (1988-1994). El temor de que el rápido cambio democrático sin un significativo progreso económico pudiera socavar todo el sistema político, el miedo a una grave crisis al estilo soviético, obligó al mandatario y a su más importante asesor, Córdoba Montoya, a prestar una mayor atención a las reformas económicas, así como a promover un acercamiento con los Estados Unidos, que se concretó en 1993 con el Tratado de Libre Comercio de Norteamérica.

El surgimiento de la Rusia postsoviética y su transición al libre mercado y a la democracia occidentalizada redujeron considerablemente la presencia e influencia rusa en México. La izquierda mexicana consideró estos cambios como una "traición" al socialismo, mientras que su carácter convulsivo y en especial el choque entre el Ejecutivo y el Legislativo durante la transición postsoviética en Rusia darían a los salinistas y a la opinión pública en general, mejores argumentos a favor de un fuerte presidencialismo. 
NOTAS

Al mismo tiempo, la semejanza entre algunos importantes elementos en las reformas políticas en Rusia y la democratización en México, así como un intento por lograr un mejor reacomodo geopolítico y geocultural expresado por el liderazgo de estas naciones en el ámbito de la creciente internacionalización e interdependencia, permitieron interpretar a algunos politólogos norteamericanos que México y Rusia eran los turning point countries, que buscaban mayor identificación con el Occidente y con ello mayor "occidentalización" de sus respectivas sociedades y políticas."

El fracaso de la política salinista reflejado en la devaluación de 1994, así como la reaparición en Rusia de una fuerte corriente nacionalista, estatista e imperialista hacen suponer que esta ilusión sobre la futura e irreversible occidentalización de México y Rusia no va a tener mucha vitalidad, al igual que la tesis sobre el "Fin de la Historia" (Fukuyama).

Rusia y México tienen sus peculiaridades y semejanzas, pero no están en el camino de ingresar al Club privilegiado de los países más ricos del mundo.

${ }^{11}$ Huntington, S. "The Clash of Civilisation", Foreing Affairs, Summer 1993.
La competencia por la atracción de la inversión extranjera y la búsqueda de nuevas alianzas regionales, tanto alejan como acercan a ambos países, en especial con relación a la Cuenca del Pacífico.

Sin duda alguna, la presencia cultural rusa en México va a perdurar mucho tiempo, sobre todo porque lo más controvertido y difícil en la relación bilateral ya quedó en el pasado. 